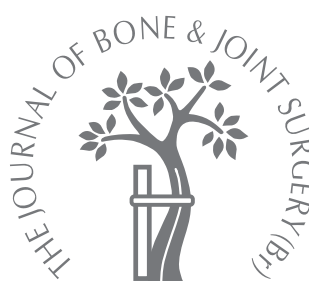

A. Gardner,

P. Millner,

M. Liddington,

G. Towns

From Leeds General

Infirmary, Leeds,

England
A. Gardner, FRCS(Trauma \& Orth), Consultant Spinal Surgeon

The Royal Orthopaedic

Hospital, Bristol Road South Northfield, Birmingham B31

2AP, UK.

I. P. Millner, FRCS(Orth), Consultant Spinal Surgeon

M. Liddington, FRCS(Plast), Consultant Plastic Surgeon

G. Towns, FRCS, Consultant Neurosurgeon

Leeds General Infirmary, Great George Street, Leeds LS1 3EX UK.

Correspondence should be sent to $\mathrm{Mr}$ A. Gardner; e-mail: acg93fm@aol.com

(C)2009 British Editorial Society of Bone and Joint Surgery doi:10.1302/0301-620X.91B9. $22101 \$ 2.00$

$J$ Bone Joint Surg [Br] 2009;91-B:1252-5.

Received 21 November 2008;

Accepted after revision 22 May 2009

CASE REPORT

\title{
Translaminar screw fixation of a kyphosis of the cervical and thoracic spine in neurofibromatosis
}

The spinal manifestations of neurofibromatosis include cervicothoracic kyphosis, in which scalloping of the vertebral body and erosion of the pedicles may render conventional techniques of fixation impossible. We describe a case of cervicothoracic kyphosis managed operatively with a vascularised fibular graft anteriorly across the apex of the kyphus, followed by a long posterior construct using translaminar screws, which allow segmental fixation in vertebral bodies where placement of the pedicle screws was impracticable.

The spinal deformities in neurofibromatosis and the difficulties in their surgical management are well documented. ${ }^{1,2}$ Translaminar screw fixation in the cervical ${ }^{3}$ and upper thoracic spines has been described. ${ }^{4,5}$ We present a case of a $90^{\circ}$ kyphosis in the cervical spine in a patient with neurofibromatosis and its operative management by anterior and posterior staged procedures using translaminar screws.

\section{Case report}

A 17-year-old girl with neurofibromatosis type 1 presented with a progressive kyphosis between C6, C7 and T1. She complained of pain in the neck and shoulder girdle without symptoms or signs of neurological involvement. The kyphosis measured $90^{\circ}$ between C6 and T1, and MRI and CT showed that the spinal cord was compressed at the level of the deformity, and there was significant scalloping of the anterior and posterior aspects of the vertebral bodies (Figs 1 and 2).

Reconstruction was undertaken in two stages, starting with a standard right-sided anterior approach to the lower cervical spine, with a three-level vertebrectomy of C5, C6 and C7 and placing a vascularised fibular graft in the defect, which was supported anteriorly with a locking plate (CSLP Synthes, Oberdorf, Switzerland). A significant correction in the sagittal plane was achieved. Preoperative halo traction had been abandoned because the patient could not tolerate any weight on her head.

She was managed in hospital between stages but was able to mobilise satisfactorily.
The second stage was undertaken a week later in order to support the anterior graft and correct the scoliosis. Through a midline posterior approach between $\mathrm{C} 1$ and $\mathrm{T} 7$, screws were placed in the lateral masses of C2, C3 and C4. Using a translaminar approach, one screw (Mountaineer; DePuy Spine, Raynham, Massachusetts) was placed alternatively in the left or right lamina of each vertebra between T2 and T7 where pedicle screw placement was impossible. Only one screw was placed at each level, as it was felt that two screws might cause a fracture at the junction of the lamina and the spinous process. The spine was decorticated and Actifuse (Apatech Inc., Foxborough, Mas-

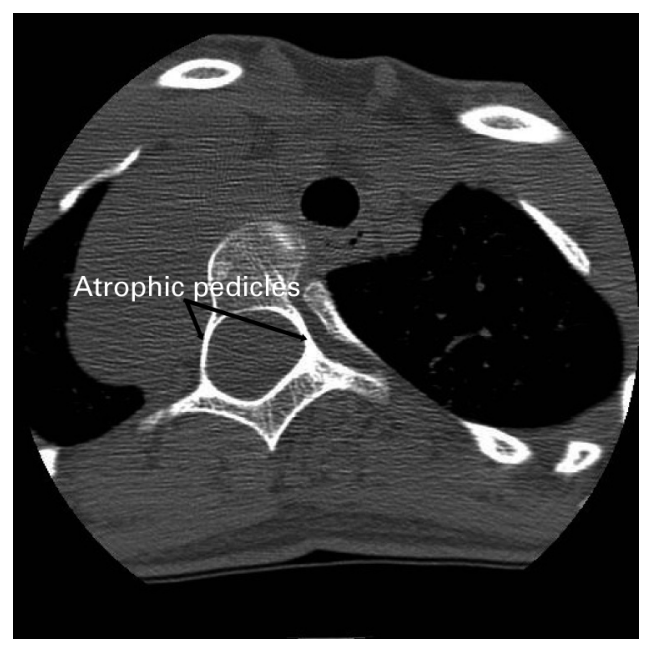

Fig. 1

Pre-operative cervical spinal axial CT scan showing atrophic pedicles but well-formed laminae. 


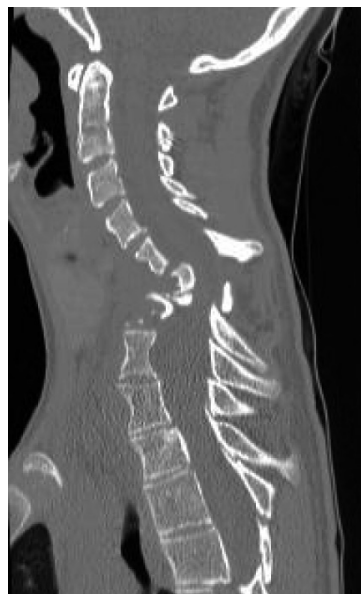

Fig. 2

Pre-operative cervical spine sagittal CT reconstruction showing the kyphotic deformity.

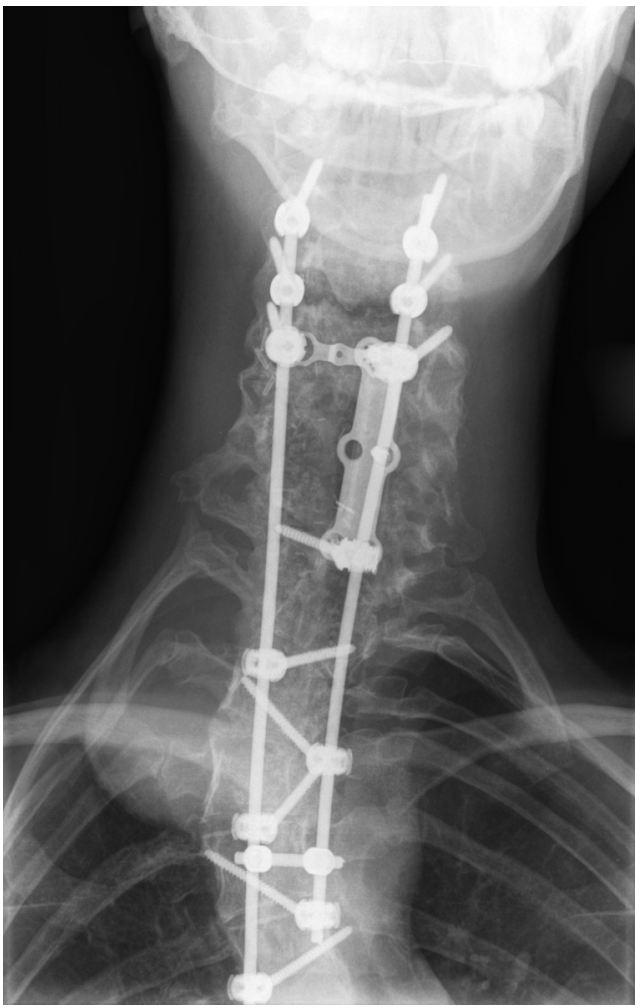

Fig. 3

Post-operative cervical spine anteroposterior radiograph showing the construct.

sachusetts), a bone graft substitute, was added to stimulate fusion.

The spine was not immobilised, either between the stages or after the second stage and as it was stable between stages

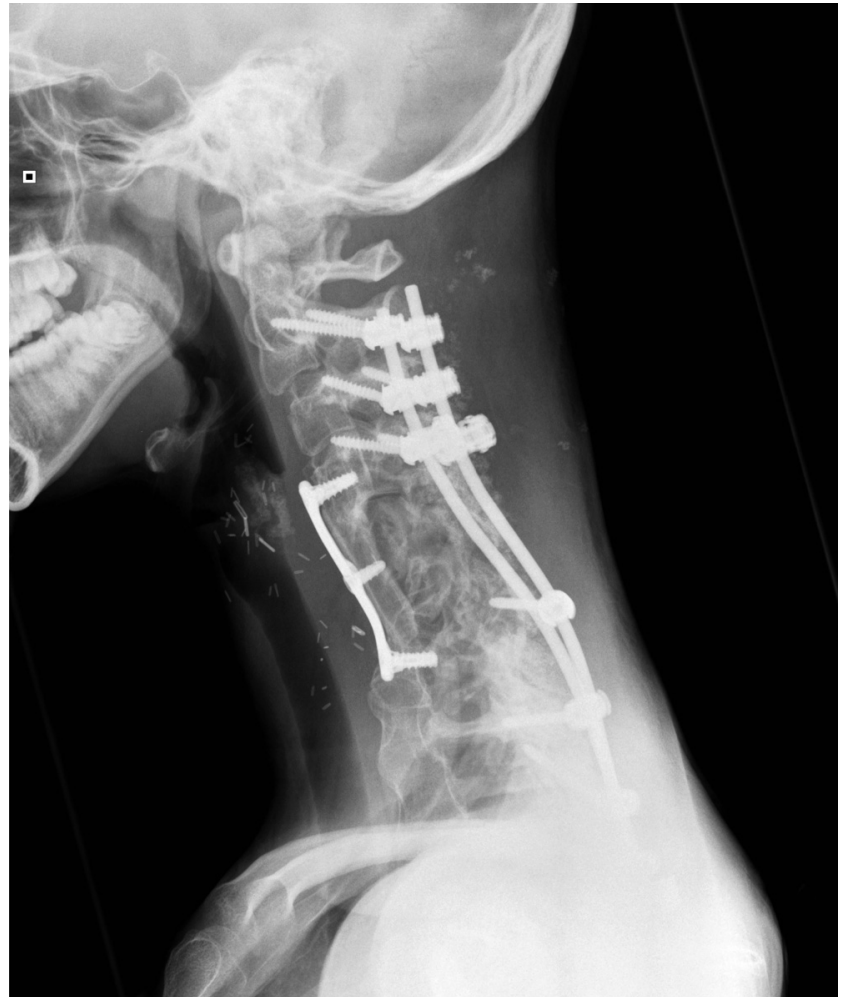

Fig. 4

Post-operative cervical spine lateral radiograph showing the construct and fusion at 18 months.

with a locked construct anteriorly and intact posterior structures with the patient in hospital, a collar was not deemed necessary. This was also true after the second stage, where, after an instrumented anterior and posterior fusion, it was felt that no further stability would be gained by external immobilisation.

Over the two stages, the kyphosis was corrected to $20^{\circ}$. Post-operative progress was complicated by a urinary track infection, which was treated by intravenous antibiotics with no long-term sequelae. Following discharge there was some wound irritation posteriorly without signs of infection. This was explored and found to be a subcutaneous mass of bone graft substitute six months after the second stage of spinal reconstruction. Once this was removed the wound healed completely. There was a significant reduction of pain in the neck and shoulder girdle and improved spinal balance in both coronal and sagittal planes. There are no neurological symptoms or signs. The patient is very pleased with her result and is back at school. At 18 months after operation there is solid fusion (Figs 3 and 4).

\section{Discussion}

Neurofibromatosis (NF) is a spectrum of conditions affecting all embryonic tissue types. Spinal deformity is seen only in the subtype NF-1, and presents with a dystrophic pattern, which may be associated with intradural anoma- 


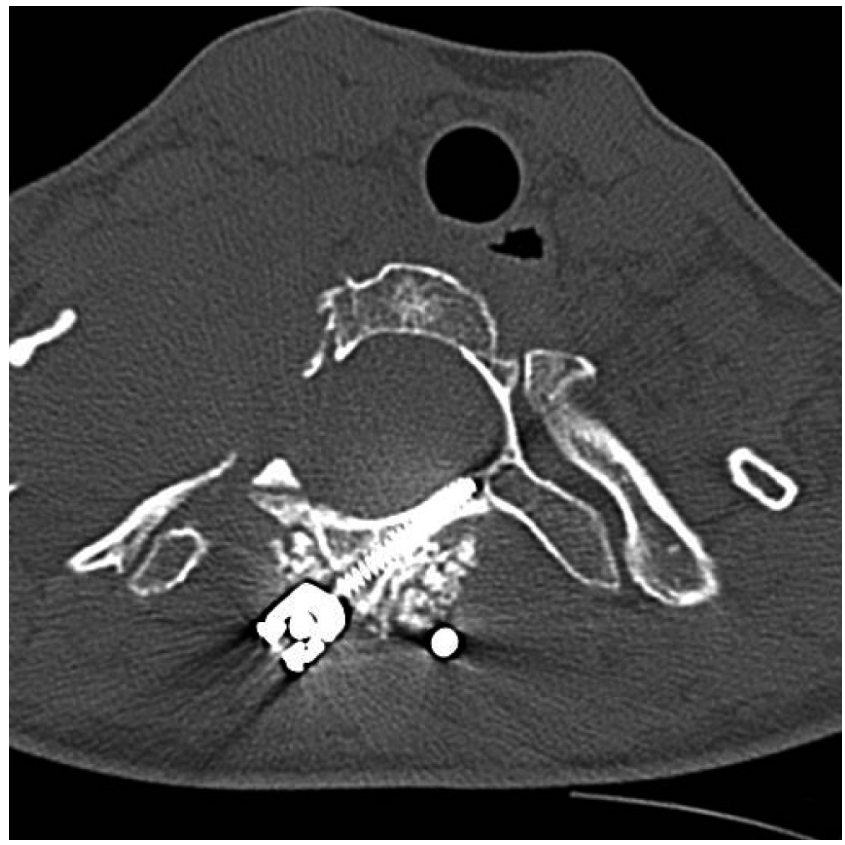

Fig. 5

Post-operative axial cervical spine CT scan showing the translaminar screw.

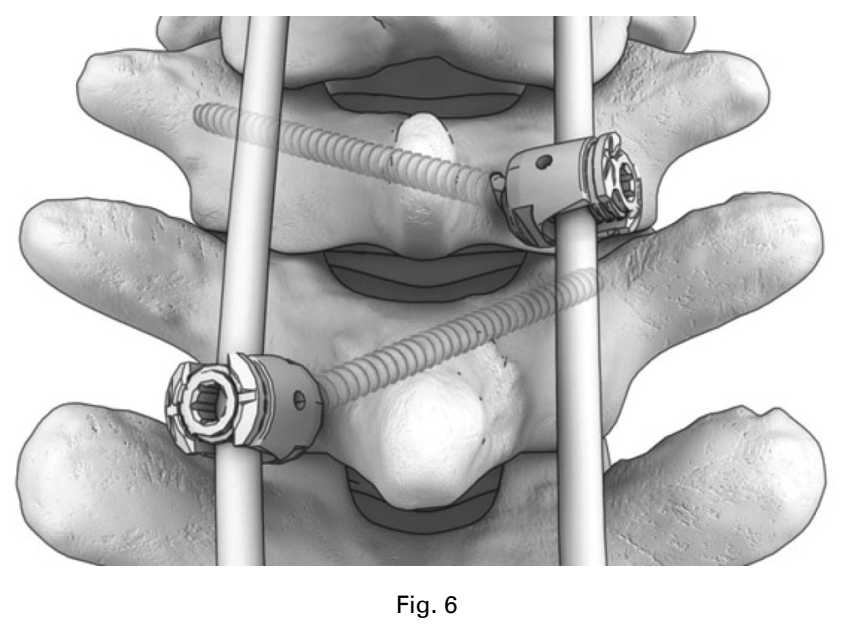

Technical posteroanterior drawing of screw insertion and landmarks highlighting the entry point on the spinous process opposite the lamina with the passage of the screw superolaterally towards the transverse process along the superior edge of the lamina.

lies and a non-dystrophic pattern. ${ }^{6}$ Akbarnia et $\mathrm{al}^{1}$ found spinal deformities in $10 \%$ of 220 patients with NF-1. Deformities are usually kyphotic in the cervical spine and scoliotic in the thoracic. ${ }^{6}$ Neurological symptoms are less common than in kyphosis elsewhere in the spine, owing to the relatively large diameter of the spinal canal. However, progressive deformity can lead to severe neurological impairment. ${ }^{7}$
The other surgical challenge seen in neurofibromatosis is secondary to vertebral body scalloping around the spinal canal. The mechanism for this is unknown, but is thought to be either due to dural ectasia secondary to an increase in intradural hydrostatic pressure, or because of an intra-spinal tumour. Scalloping can cause difficulties when instrumenting the spine as the pedicles, lateral masses and vertebral bodies may be insufficient to hold a screw. Sublaminar wires can be used, but require the canal to be opened where the dilated, thin, ectatic dura is at risk of penetration.

Spinal fusion in neurofibromatosis is fraught with difficulties. Previous authors have recommended pre-operative traction, anterior and posterior fusion using abundant bone graft and prolonged immobilisation, or third-generation segmental instrumentation. ${ }^{2,8}$ Anterior structural grafting is recognised as a way of resisting progressive kyphosis, especially in neurofibromatosis, and is recommended in dystrophic curve patterns in order to reduce the risk of pseudarthrosis. A vascularised anterior strut graft has the added benefit of avoiding resorption by creeping substitution as the graft incorporates and reduces the risks of fracture and nonunion, especially in neurofibromatosis. ${ }^{9}$

The use of translaminar screws has been described in the cervical spine, especially in C2, ${ }^{3,10}$ the first and second thoracic vertebrae, ${ }^{4}$ and as isolated screws in scoliosis constructs, ${ }^{5}$ but hitherto not as the principal method of fixation in a long posterior construct bridging the cervicothoracic junction. The technique for cannulating the lamina and placing a translaminar screw is similar to that for inserting pedicle screws. The entry point is marked on the spinous process opposite the lamina in question and a pilot hole created. A small pedicle awl (maximum diameter $1.8 \mathrm{~mm}$ ) is passed along the lamina in line with its superior edge, aiming for the junction of the transverse process and superior facet laterally, in order to miss the neural foramen. The track is felt with a pedicle feeler, measured, tapped, and the screw inserted (Fig. 5). The screws used in this case were $4.35 \mathrm{~mm}$ in diameter and connected to a $3.5 \mathrm{~mm}$ diameter titanium rod (Figs 6 and 7).

This technique differs from that of translaminar transfacetal screw placement described by Magerl, ${ }^{11}$ in which the screw passes from the midline through a small part of the lamina and through the inferior facet joint below the lamina, to finish in the transverse process. The screw passes inferiorly and laterally from the midline and the technique is described for facet fusion, independent of rods, for the non-deformed spine. In our technique, the screws were used to obtain rod fixation to the spine, thereby allowing a large portion of spine to be instrumented with rods but not to obtain facet fusion, as this is achieved by decortication and grafting at the instrumented levels. This technique was particularly appropriate in this case, as the dystrophic deformity precluded a pedicle screw construct distal to the cervical spine. In constructs between C2 and C3, laminar screws have been shown to be equivalent to pedicle screws in $\mathrm{C} 2$ in terms of stability when combined with lateral mass 


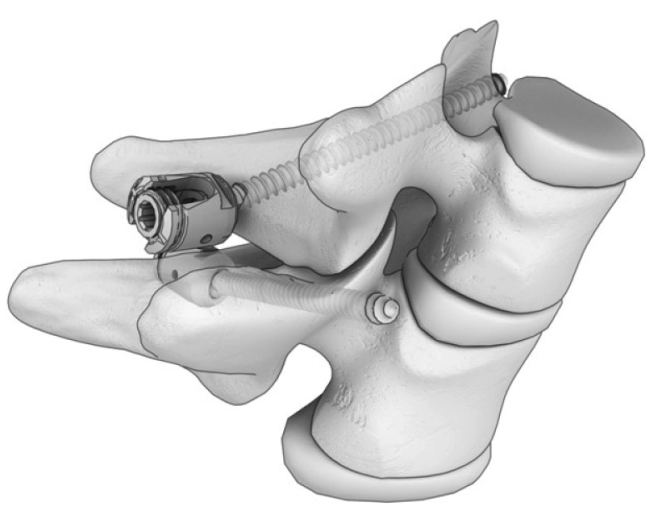

Fig. 7

Oblique drawing of screw insertion and landmarks highlighting the passage of the screw superior to the neural foramen.

screws in $\mathrm{C} 3{ }^{12}$ although data for this construct elsewhere in the spine are not available.

In this case of cervical kyphosis in neurofibromatosis, a combined anterior vascularised fibula graft and posterior instrumented fusion using translaminar screws achieved a good clinical outcome and successful fusion. Translaminar screws provided a method of segmental instrumentation which would not otherwise have been possible because of erosion of the vertebral body. We feel that the technique can be used reliably in the thoracic spine and adds to the options for posterior instrumentation where the anatomy has been distorted or destroyed by the underlying disease.

The author or one or more of the authors have received or will receive benefits for personal or professional use from a commercial party related directly or indirectly to the subject of this article.

\section{References}

1. Akbarnia BA, Gabriel KR, Beckman E. Prevalence of scoliosis in neurofibromatosis. Spine 1992;17(Suppl 8):244-8.

2. Tsirikos Al, Saifuddin A, Noordeen MH. Spinal deformity in neurofibromatosis type-1: diagnosis and treatment. Eur Spine J 2005;14:427-39.

3. Wright NM. Posterior C2 fixation using bilateral, crossing C2 laminar screws: case series and technical note. J Spinal Disord Tech 2004;17:158-62.

4. Kretzer RM, Sciubba DM, Bagley CA, et al. Translaminar screw fixation in the upper thoracic spine. J Neurosurg Spine 2006;5:527-33.

5. Lewis SJ, Canavese F, Keetbaas S. Intralaminar screw insertion in the thoracic spine in children with severe deformities. Spine 2009;34:251-4.

6. Crawford AH. Neurofibromatosis. In: Weinstein SL, ed. The pediatric spine: principles and practice. Second ed. Philadelphia: Lippincott Williams and Wilkins, 2001:471-89.

7. Goffin J, Grob D. Spondyloptosis of the cervical spine in neurofibromatosis: a case report. Spine 1999;24:587-90.

8. Winter RB, Lonstein JE, Anderson M. Neurofibromatosis hyperkyphosis: a review of 33 cases with kyphosis with 80 degrees or greater. J Spinal Disord 1988;1:39-49.

9. Nijland EA, van den Berg MP, Wuisman PI, et al. Correction of a dystrophic cervicothoracic spine deformity in Recklinghausen's disease. Clin Orthop 1998:349:149-55.

10. Wang MY. Cervical crossing laminar screws: early clinical results and complications. Neurosurgery 2007;61(5 Suppl 2):311-15.

11. Magerl F. Translaminare verschraubung der intervertebralgelenke. In: Weber BG, Magerl F, eds. Fixateur. Berlin: Springer-Verlag, 1985;315-17.

12. Reddy C, Ingalhalikar AV, Channon S, et al. In vitro biomechanical comparison of transpedicular versus translaminar C-2 screw fixation in C2-3 instrumentation. J Neurosurg Spine 2007;7:414-18. 